\section{To the heart of the matter}

Roy Porter

Vampires, Burial, and Death: Folklore and Reality. By Paul Barber. Yale University Press:1988. Pp.236. £14.95, \$30.

PAuL Barber's inquiry into vampires, fact and fiction, is a gem in the literature of debunking. We would all recognize a vampire if we saw one, that 'undead' soul who rises from the grave to gorge himself upon the blood of the living, thereby creating further generations of vampires: he would be tall, clad in a black cloak, and endowed with terrifyingly sharp fangs. But we would be wrong. For Barber reveals that this Count Dracula figure, so familiar from the movies, bears scant relation to the traditional 'revenant' who is so powerful a presence in Central and Eastern European folk memory. Examination of recorded sightings shows the vampire was quite different: above all, podgy and florid of complexion, and no mention of those teeth.

What are we to make of this traditional vampire? Folk wisdom had it that vampires were those who had died before their time (perhaps as suicides or murder victims) and, for that reason, were destined to find no rest. Their soul did not depart in peace, nor did their body decompose, and so they rose from their graves to haunt the living, whose blood they would suck for sustenance. They had to be captured, and then a timely stake through the heart or cremation would ensure that they would never walk again.

Of course, Barber is not suggesting that these supernaturalist beliefs should be taken seriously. What fascinates him above all are the attempts that intellectuals have made to provide 'scientific' explanations of well-attested 'vampire' phenomena, such as undecomposed bodies found outside their graves. Once popular, for instance, was the notion that the dead walk because they were never dead at all, but were unfortunates who had suffered premature burial, while in a deep coma, and who had regained consciousness and clawed their way out of their coffins. But such 'naturalistic' accounts are no less incredible than the old supernatural stories themselves: they are merely different versions of folklore.

A little elementary forensic pathology, Barber advises, will reveal the truth that lies at the heart (so to speak) of vampire myths. If the vampire is the body that refuses to decompose, that should not surprise us: as the gravedigger in Hamlet knew so well, under all sorts of climatic and soil conditions corpses do indeed

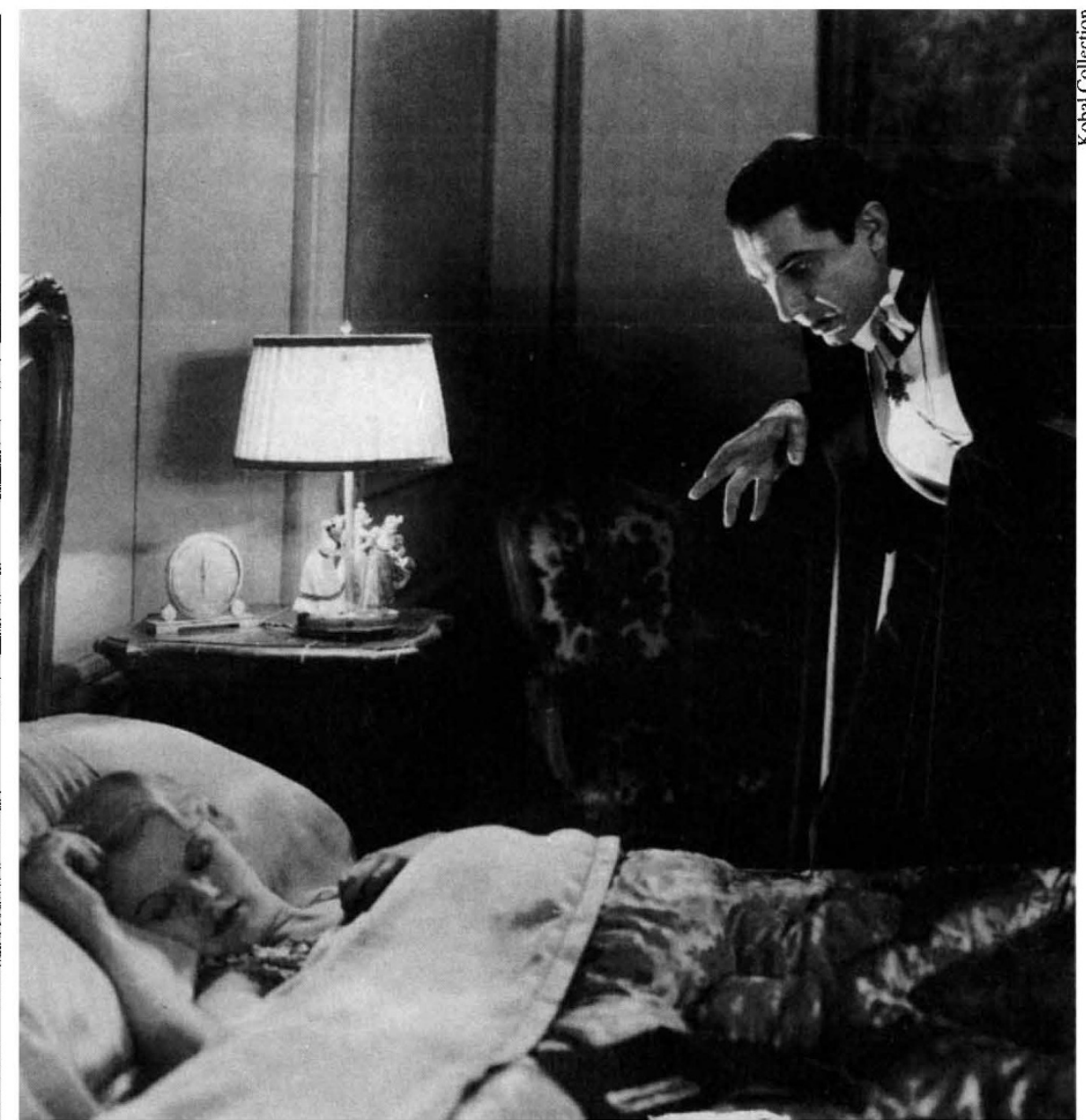

Wot no fangs? Bela Lugosi as Dracula approaches a prospective victim.

disintegrate very slowly. The presence of liquid blood around the mouth supposedly the evidence of midnight snacks - is likewise easily explained: blood often does not coagulate. Moreover, the bloated condition of such corpses is not, of course, the result of gorging on blood, but the product of gaseous build-up. And it is the escape of these gases which accounts for the moans when the stake is finally driven through the heart. Floods and subsidence readily explain why buried corpses, or at least a hand or foot, rise to the surface from time to time.

In other words, corpses often do not look dead in the way that people expect them to, thus explaining the vampire myth that they are still alive. Belief in revenants is therefore a quite intelligent attempt to build a theory upon experience: pathological science is then needed to give the true explanation.

Two conclusions emerge from Barber's sleuth work. One is that the so-called 'scientific' explanations which scientists, past and present, often devise to explain, or explain away, the odd, the marvellous, the praeternatural and the paranormal, are often monuments of misplaced ingenuity, far-fetched in themselves and not even consonant with reported data. Science thus has a mythological folklore of its own.
The other underlines the terror that death strikes into the living. Through complex burial practices, mankind has always gone to immense trouble in disposing of the dead. Partly out of respect, indeed, but not least out of a need to propitiate the dead while at the same time immobilizing them. Fearing that the dead are those who are the cause of death, we have created secure burial mounds and coffins as much to protect the living from molestation by the dead as to honour the corpse. Even when safely buried, the suspicion lurks that they are not quiet, and hence they may need to be slain and slain again.

Barber's book is a convincing exercise in mental archaeology. It should be read alongside Pietro Camporesi's The Incorruptible Flesh (Cambridge University Press, 1988) which investigates a parallel phenomenon: the vast fascination which traditional Christianity has had for the flesh of saints and martyrs. We should not be complacent today about our own enlightenment in these matters, as public panic over the disposal of the bodies of AIDS victims amply shows.

Roy Porter, Wellcome Institute for the History of Medicine, London, is currently at the William Andrews Clark Memorial Library, 2520 Cimarron Street, Los Angeles, California 90018, USA. 